\title{
Esfuerzo de bienestar y pobreza desde el enfoque monetarista y de capacidades: análisis transnacional en América Latina y el Caribe (1990-2010)
}

\author{
Gibrán Cruz-MarTínez \\ Universidad Autónoma de Chile \\ gcruz@ichem.cl
}

Recibido: 04-06-2014

Aceptado: 01-10-2015

\section{Resumen}

Existe una abundante evidencia empírica sobre la relación negativa entre el esfuerzo de bienestar y la pobreza. Sin embargo, los indicadores de pobreza tradicionalmente utilizados han sido representativos del enfoque monetarista, excluyendo del análisis su realidad multidimensional. Utilizando tres técnicas de regresión para el periodo 1990-2010 y controlando por factores demográficos y cíclicos, en este trabajo se ha evaluado la relación entre esfuerzo de bienestar en términos de gasto social per cápita y la pobreza en 21 países de la región. Para medir la pobreza desde el enfoque monetarista se han considerado dos indicadores: la proporción de población con ingresos inferiores a la canasta básica de alimentos y servicios (PM1) y la proporción de población con ingresos inferiores al 50\% de la mediana de ingresos per cápita (PM2). Desde el enfoque de capacidades se ha valorado la proporción de población con insuficiencia alimentaria (PC1) y la proporción de la población sin acceso a agua potable ni servicio de saneamiento (PC2). Los resultados confirman que el gasto social es útil para explicar los cambios en la pobreza (PM1, PC1 y PC2), ya que existe una alta correlación negativa y significativa entre las variables antes y después de controlar para factores demográficos y cíclicos. En dos de las técnicas de regresión el gasto social per cápita no presentó una relación negativa con la variable PM2. Por último, el gasto social per cápita fue el más útil para explicar los cambios en la pobreza desde el enfoque de capacidades.

Palabras clave: gasto social; pobreza; esfuerzo de bienestar; América Latina y el Caribe; Estado de Bienestar; capacidades. 


\title{
Welfare Effort and Poverty from the Monetary and Capabilities Approach: A Cross-Country Analysis in Latin American and the Caribbean (1990-2010)
}

\begin{abstract}
There is abundant empirical evidence on the negative relationship between welfare effort and poverty. However, poverty indicators traditionally used have been representative of the monetary approach, excluding its multidimensional reality from the analysis. Using three regression techniques for the period 1990-2010 and controlling for demographic and cyclical factors, this paper examines the relationship between social spending per capita — as the indicator of welfare effort - and poverty in up to 21 countries of the region. The proportion of the population with an income below its national basic basket of goods and services (PM1) and the proportion of population with an income below $50 \%$ of the median income per capita (PM2) were the two poverty indicators considered from the monetarist approach to measure poverty. From the capability approach the proportion of the population with food inadequacy (PC1) and the proportion of the population without access to improved water sources or sanitation facilities (PC2) were used. The findings confirm that social spending is actually useful to explain changes in poverty (PM1, PC1 and PC2), as there is a high negative and significant correlation between the variables before and after controlling for demographic and cyclical factors. In two regression techniques, social spending per capita did not show a negative relationship with the PM2. Countries with greater welfare effort for the period 1990-2010 were not necessarily those with the lowest level of poverty. Ultimately social spending per capita was more useful to explain changes in poverty from the capability approach.
\end{abstract}

Keywords: Social Spending; Poverty; Welfare Effort; Latin America and the Caribbean; Welfare State; Capabilities.

\section{Referencia normalizada}

Cruz-Martínez, G. (2015): "Esfuerzo de bienestar y pobreza desde el enfoque monetarista y de capacidades: análisis transnacional en América Latina y el Caribe (1990-2010)", Política y Sociedad, 52 (3), pp. 631-659.

Sumario: 1. Introducción. 2. Diseñode investigación. 3. Resultados.4. Conclusión. 5. Bibliografía.

$$
* * *
$$

\section{Agradecimientos}

Esta investigación fue posible en parte por la financiación del Ministerio de Educación, Cultura y Deporte (FPU AP2009-0069). Agradezco a Manuel Sánchez de Dios, Omar Ramírez, Francisco Pesante, Mayrin García y a las/os dos revisoras/es anónimas/os por sus comentarios en versiones anteriores del manuscrito, referencias y/o indicaciones metodológicas de los análisis utilizados. Las carencias, por supuesto, son mi responsabilidad. 


\section{Introducción}

Diversos investigadores han demostrado que efectivamente hay una relación negativa entre las variables gasto social y pobreza. Caminada et al. (2012), controlando diferencias macroeconómicas y demográficas ${ }^{1}$, confirman la relación negativa entre gasto social y pobreza en 22 países de la OCDE para el periodo 1985-2005. Dafermos y Papatheodorou (2012) confirman que las transferencias sociales en efectivo y principalmente las transferencias que no incluyen pensiones, ejercen un impacto significativo en la reducción de la desigualdad y pobreza. Smeeding $(2005,2006)$, Comisión Europea (2009), Nolan y Marx (2009), Kenworthy (1999) y Scruggs y Allan (2006), entre muchos otros, confirman en sus investigaciones esta relación negativa entre el nivel de gasto social y la pobreza. Sin embargo, investigadores como Josifidis et al. (2010) y Cárdenas Rodríguez (2009) han demostrado que si bien puede haber una relación negativa entre las dos variables en un conjunto de países, no necesariamente los países con mayor gasto social son los que presentan menores niveles de pobreza.

El propósito principal del presente artículo es comprobar el grado de fortaleza y significación de la correlación entre la pobreza y gasto social después de controlar para factores demográficos y cíclicos, en los países de la región de América Latina y el Caribe. En cierta manera se trata de confirmar que los resultados de Caminada et al. (2012) y demás investigadores mencionados anteriormente son ciertos también para la región latinoamericana.

El gasto social per cápita es el indicador que representa la variable explicativa, mientras que la pobreza es la variable dependiente y está representada por cuatro indicadores definidos desde el enfoque monetarista y desde el enfoque de capacidades. La proporción de población con ingresos inferiores a la canasta básica de alimentos y servicios (PM1) y la proporción de población con ingresos inferiores al 50\% de la mediana de ingresos per cápita disponibles (PM2) son los dos indicadores de la pobreza desde el enfoque monetarista. Desde el enfoque de capacidades se utiliza la proporción de población con insuficiencia alimentaria (PC1) y la proporción de la población sin acceso a agua potable ni servicio de saneamiento (PC2). Mientras que la proporción de población en edad avanzada, proporción de población desempleada y el PIB per cápita fungen como controles. Para corroborar la relación entre las variables, se utilizan tres técnicas de investigación las cuales se profundizan en la presentación del diseño de la investigación.

El artículo se organiza de la siguiente manera. En la próxima sección se presenta el diseño de la investigación junto a la variable explicativa y dependiente con sus respectivos indicadores. Se procede a presentar los resultados de las tres técnicas de regresión utilizadas y se finaliza con una conclusión general sobre los principales hallazgos.

\footnotetext{
${ }^{1}$ Nivel de desempleo, PIB per cápita y proporción de personas en edad avanzada.
} 


\section{Diseño de investigación}

Las preguntas de investigación que se abordan en este artículo son las siguientes: ¿qué fortaleza presenta la relación entre el esfuerzo de bienestar y el nivel de pobreza en América Latina y el Caribe? ¿Los países con un mayor esfuerzo de bienestar son los que presentan un menor nivel de pobreza? ¿Se mantiene la relación entre las variable dependiente y explicativa a través del periodo temporal considerado en esta investigación (1990-2010)? ¿El esfuerzo del bienestar es una variable útil tanto para explicar los cambios en la pobreza desde el enfoque monetarista como del enfoque de capacidades?, ¿La relación entre las variables mantiene su fortaleza y facultades explicativas al incorporar controles en el modelo de regresión?

Estas preguntas de investigación han sido abordadas mediante técnicas de investigación cuantitativas. En primer lugar se realiza una regresión lineal por mínimos cuadrados entre los valores promedios del gasto social y los cuatro indicadores de pobreza para el periodo 1990-2010. En segundo lugar, se realiza una regresión lineal por mínimos cuadrados entre la variable explicativa y dependiente para 1990, 1995, 2000, 2005 y 2010 controlando la proporción de población en edad avanzada, proporción de población desempleada y el producto interior bruto. En tercer lugar se realiza una regresión lineal por mínimos cuadrados a una serie temporal transnacional entre gasto social per cápita y pobreza con los errores estándares del panel corregidos (PCSE), en el periodo 1990-2010 y utilizando los mismos tres controles.

¿Por qué incluir controles al modelo de regresión entre la variable explicativa y dependiente? Díez Medrano (1992) alerta sobre la necesidad de evitar suponer una causalidad entre variables por el hecho de presentar una alta correlación. "La única manera para establecer una relación causal (...) consiste en eliminar cuantas variables explicativas potenciales sea posible". Esto es viable mediante la inclusión de variables de control en el análisis relacional, con el propósito de asegurar que la relación entre una variable X y una Y no sea fraudulenta (1992: 18). De igual manera los resultados de esta investigación pretenden demostrar la relación entre variables, sin asumir necesariamente una causalidad entre estas.

En este artículo se realiza un análisis descriptivo de la relación entra las variables, sin embargo no se examinan las causas y explicaciones de los niveles de pobreza entre los países de la región. Como señala Caminada et al. (2012) y Gottschalk y Smeeding (2000) un análisis que explique los niveles y estructura de la pobreza "debería estar basado en teorías que aborden al menos los siguientes factores que pueden tener un impacto en los niveles de pobreza: diferencias en los mercados de trabajo que afecten a los ingresos de los miembros de un hogar; diferencias demográficas como el envejecimiento de la población y el crecimiento de hogares monoparentales, que afectan tanto las necesidades de la familia como las decisiones en el mercado laboral; y las diferencias entre países en las políticas fiscales y de transferencias que no solo afectan 
los ingresos familiares directamente sino que pueden afectar también las decisiones de transferencias e inversiones" (Caminada et al., 2012: 117).

Factores demográficos y cíclicos fueron incorporados al análisis de regresión entre el gasto social y la pobreza. Los cambios en el gasto social puede estar causados por números factores como el aumento de beneficiarios de pensiones debido al envejecimiento de la población, por el aumento en prestaciones por desempleo debido a los ciclos y fallos de la economía de mercado, y por el aumento de la riqueza de un país debido a que puede afectar a la proporción de recursos destinado a gasto social. Según la literatura académica, los tres controles estadísticos a utilizar aparentan ser los más relevantes para un análisis transnacional (Caminada et al., 2012; Nolan y Marx, 2009; OECD, 2008; Cantillon et al., 2003).

\subsection{Variable explicativa: el esfuerzo de bienestar}

Según Amenta (1993: 751) se puede considerar el esfuerzo de bienestar "como la proporción del ingreso que un país destina a la provisión publica social". Según Olaskoaga et al. (2013) el gasto social como porcentaje del PIB (esfuerzo del bienestar) ha sido convencionalmente utilizado como indicador en análisis comparativos para representar el nivel de desarrollo del Estado de bienestar. Segura-Ubiergo (2007) construyó un índice de esfuerzo del bienestar utilizando tres indicadores de gasto social y uno de cobertura ${ }^{2}$. Es tan común la utilización del gasto social como indicador del esfuerzo de bienestar de un Estado que Amenta (1993: 750) se refiere al Estado de bienestar como "la provisión pública y el gasto público social".

Sin embargo, cabe conceptualizar el Estado de bienestar como una variable multidimensional (Cruz-Martínez, 2014). Así el gasto social es solo una de las dimensiones que se deben de tomar en consideración a la hora de evaluar el desarrollo del Estado de bienestar. Es necesario incorporar indicadores de cobertura de los programas de bienestar, así como indicadores de resultados de las instituciones del bienestar. Sin embargo, para realizar un análisis relacional temporal y transnacional, la dimensión del gasto social es muy útil. Jensen (2011) reconoce que hay un consenso entre los investigadores del Estado de bienestar en cuestionar el gasto social como indicador representativo del esfuerzo del bienestar. Sin embargo considera que el gasto social es la medida más adecuada para analizar las diferencias transnacionales en cuanto a la voluntad de los

${ }^{2}$ Varios han sido los investigadores que han evaluado la expansión del Estado de bienestar - entendida como esfuerzo de bienestar - por medio del uso de teorías explicativas de Estados de bienestar europeos. Entre estos se encuentran: Huber y Stephens (2012: 14-18), Wilensky (1975), Pampel y Williamson (1989), Hicks (1999), Castles (1985), Heclo (1974), Orloff (1993), Skocpol (1988), Weir et al. (1988), Stephens (1979), Korpi (1983), Esping-Andersen (1990), Rodrik (1998), Cameron (1978), Ames (1987), Sloan y Tedin (1987), Huber et al. (2008) y Brooks y Manza (2007). 
actores decisores para promover programas de bienestar sanitarios y educativos, en donde las diferencias entre países en tipos de ayuda y criterios de beneficios es mínima.

Como indicador de la variable esfuerzo de bienestar de los países de la muestra se ha utilizado el gasto social per cápita. Los datos de este indicador provienen de la base de datos de la Comisión Económica para América Latina y el Caribe (CEPAL). Según la CEPAL el gasto social per cápita "es la estimación, por persona, de la asignación de recursos públicos al gasto en sectores sociales a precios constantes de 2005". El valor reflejado es la sumatoria del "gasto público en educación, salud, seguridad social, trabajo, asistencia social, vivienda, agua y alcantarillado"3 (CEPAL, s/f).

\subsection{Variable dependiente: la pobreza}

Existe una gran cantidad de definiciones de la pobreza, aunque esencialmente es la situación en que se encuentra un individuo cuando no puede disfrutar una vida en plena libertad. Según Bérgolo et al. (2010: 4-5), un individuo se encuentra en pobreza cuando presenta carencias que "limitan su posibilidad de satisfacer un conjunto de elementos básicos para el desarrollo de una vida plena en sociedad".

Ahora bien, la gran cuestión es cómo medir la pobreza y es en este punto cuando comienzan las diferencias entre defensores del enfoque monetarista y defensores del enfoque de capacidades. La medición de la pobreza es una labor que abarca aspectos teóricos y metodológicos muy variados. Involucra generalmente dos elementos: la identificación de los pobres y la agregación del bienestar de los considerados como pobres en una medida (Feres y Mancero, 2001: 5). Una vez conceptualizada la pobreza, es necesario establecer una medida (línea, techo) mediante la cual se pueda cuantificar los individuos en pobreza. ¿Qué es ser pobre? ¿Quiénes son pobres? son, pues, las dos preguntas que guían el análisis descriptivo de los indicadores a utilizar.

Para el análisis relacional en este trabajo se han utilizado cuatro indicadores de pobreza, de los cuales dos presentan la pobreza desde el enfoque monetarista, y los restantes la pobreza desde el enfoque de capacidades.

\subsubsection{Enfoque Monetarista (ingresos)}

La pobreza desde el enfoque monetarista es entendida como la incapacidad de un individuo en alcanzar un nivel mínimo de bienestar ${ }^{4}$. Ravallion (1992: 4) argumenta que "existe pobreza en una sociedad cuando una o más personas no alcanzan un nivel de

${ }^{3}$ Para abundar sobre la metodología del gasto social per cápita según la CEPAL dirigirse a la ficha técnica en $<$ http://interwp.cepal.org/sisgen/SisGen_MuestraFicha.asp?indicador=133\&id_estudio=6>.

${ }^{4}$ Se entiende por bienestar "aquella situación en la que se está cuando se satisfacen las necesidades, y cuando se prevé que han de seguir siendo satisfechas" (Morales, 1994: 604). 
bienestar material, como un mínimo razonable para los estándares de esa sociedad". Para el Banco Mundial (1990: 26-27) la pobreza es definida como "la incapacidad para alcanzar un nivel de vida mínimo". La Organización de Naciones Unidas utiliza la medida de pobreza defendida por el Banco Mundial de un dólar diario (precio poder adquisitivo) para identificar las personas en pobreza extrema.

Según Spicker (2009: 182) "generalmente se considera que una línea de pobreza es un umbral, en términos de ingreso o de riqueza, por debajo del cual las personas pueden ser consideradas pobres". Ahora bien, esa línea de pobreza puede estar basada en una consideración relativa o absoluta. Ambas son interpretaciones de la manera en que se construyen socialmente las necesidades del objeto estudiado. La consideración absoluta se apoya en que las necesidades de un individuo son independientes del nivel de renta o riqueza del entorno. Mientras que la consideración relativa otorga relevancia al nivel de riqueza ya que las necesidades surgen de la comparación del individuo con su entorno.

El enfoque monetarista sigue un criterio utilitarista que considera la "línea de pobreza" como una buena medida para presentar el nivel de pobreza de una población, ya que los seres racionales maximizarán sus recursos para satisfacer sus necesidades y garantizar su bienestar. Aunque el principal problema que presenta este enfoque es que presupone que todo individuo actuará racionalmente en todo momento.

En este sentido, por ejemplo, Samuelson (1974) vincula el bienestar con la utilidad que reporta un importe monetario gastado. Kuklys y Robeyns (2004) avalan que se pueda utilizar el ingreso monetario gastado por cada individuo en su respectiva comunidad como un insumo fundamental para analizar el bienestar. La lógica de que un cierto ingreso permite obtener los recursos y bienes necesarios para maximizar la utilidad de un individuo, en términos de satisfacer sus riesgos sociales y garantizar su bienestar, es un hecho para los utilitaristas que analizan la pobreza desde el enfoque monetarista.

En el trabajo se han utilizado dos indicadores de privaciones individuales monetaristas que sufre la población en pobreza. El primero establece la línea de pobreza en el coste de la canasta básica de alimentos y servicios a nivel nacional. El segundo indicador establece la línea de pobreza en el $50 \%$ de la mediana de ingresos per cápita a nivel nacional.

\section{a) Indicador de pobreza monetaria 1 (PM1): canasta básica de alimentos y servicios}

El primer indicador de pobreza monetarista es la proporción de personas que se encuentren por debajo de la línea de la pobreza establecida por la CEPAL. La pobreza es considerada por la CEPAL como la situación en que una persona no dispone de los recursos económicos (ingresos) suficientes que le permitan adquirir los alimentos y servicios "básicos". Las canastas básicas de alimentos y servicios son específicas para cada país y respetan las estructuras de consumo y preferencias de servicios nacionales. 
Por esta razón este indicador presenta la pobreza desde una perspectiva relativa. Los datos utilizados provienen de la CEPALSTAT.

Desde el punto de vista monetarista la generación de suficientes ingresos para poder adquirir bienes y servicios por encima de niveles de pobreza brindará la utilidad necesaria para que el hogar/individuo no se sienta en pobreza. Esto será debido a que todo individuo actúa racionalmente y dedica la totalidad de sus ingresos a satisfacer sus necesidades básicas.

\section{b) Indicador de pobreza monetaria 2 (PM2): mediana de ingresos per cápita}

Este segundo indicador de pobreza relativa y monetaria atiende a la distribución de ingresos. La mediana de ingresos per cápita es utilizada principalmente por la OCDE y la Unión Europea como línea de pobreza. La Unión Europea considera a un individuo en riesgo de pobreza si se encuentra residiendo en un hogar con un ingreso disponible inferior al $60 \%$ de la mediana de ingresos. Mientras que la OCDE ubica el umbral de pobreza en el $50 \%$ de la misma. Ambos organismos ajustan los ingresos al tamaño y composición del hogar. Como segundo indicador de pobreza monetaria en esta investigación se ha utilizado el $50 \%$ de la mediana de ingresos per cápita. Los datos también han sido extraídos de la CEPALSTAT.

Desde el punto de vista monetarista se puede considerar que todo aquel que supere el umbral de pobreza establecido será capaz de satisfacer sus necesidades y no sufrirán la exclusión social. Aunque la OECD (2008) reconoce las limitaciones de la pobreza vista como renta baja por presentar una sola dimensión o parte de la pobreza, también la defiende por su fiabilidad a la hora de realizar análisis comparados entre países.

\subsubsection{Enfoque de Capacidades}

El enfoque de capacidades deriva del planteamiento de Amartya Sen. Para este investigador la pobreza resulta del fracaso para obtener un nivel mínimo de capacidades básicas $^{5}$, necesarias para el desarrollo y calidad de vida de una persona (Sen, 1999). Un individuo se considera en pobreza si no tiene desarrolladas las capacidades ${ }^{6}$ que le brinde libertad garantizando su bienestar.

${ }^{5}$ Una capacidad básica es la habilidad de satisfacer ciertos funcionamientos elementales y crucialmente importantes (Sen, 1992: 45).

${ }^{6}$ Es necesario distinguir entre las capacidades, los bienes, las funcionalidades (características) y las utilidades. Según Spicker (2009: 59) "las capacidades son aquellas habilidades básicas que la gente necesita para funcionar en su vida, y las características son los medios a través de los cuales estas necesidades son efectivizadas". Sen (1983: 160) ejemplifica estas diferencias utilizando una bicicleta, distinguiéndola como un bien, que efectivamente tiene varias características o funcionalidades. Haciendo referencia a la funcionalidad de transporte que tiene una bicicleta, el autor explica los diferentes conceptos de la siguiente 
Según Sen (1983), la pobreza supone privación de habilidades básicas para funcionar en la vida como es, por ejemplo, estar adecuadamente alimentado, saber leer y escribir o tener una vida prolongada y sana. El enfoque de Sen se diferencia del utilitarista pues "sostiene que una medida monetaria del nivel de vida no puede reflejar el abanico de las oportunidades que los individuos tienen para alcanzar un nivel de vida mínimamente adecuado, ya que no toma en cuenta las capacidades individuales para transformar los bienes en satisfactores de necesidades. (...) Las capacidades son básicas para el ejercicio de la libertad, por lo que la pobreza limita el ejercicio de la libertad personal" (Spicker, 2009: 59). Sen argumenta que poseer un bien no ofrece información sobre lo que el individuo pueda hacer con ese bien.

Según Sen (1983: 161) la pobreza es una noción absoluta en el espacio de las capacidades, pero muy a menudo toma una forma relativa en el espacio de los bienes o sus funcionalidades. En un análisis comparado - una vez consideradas las diferencias relativas que existan entre la población a la hora de transformar bienes satisfactores en capacidades - el indicador de pobreza será absoluto ya que considerará la probabilidad de que los individuos transformen efectivamente la funcionalidad de los bienes en capacidades.

Diversos académicos e investigadores (Alkire, 2002; Alkire y Black, 1997; Clark, 2002, 2003; Desai, 1995; Nussbaum, 1990, 1995, 2000, 2003; Robeyns, 2003) se han dado a la tarea de operacionalizar la teoría de capacidades de Sen, proponiendo indicadores para capacidades y a su vez enumerando capacidades básicas, según su criterio personal. El Índice de Pobreza Multidimensional (IPM) de Alkire y Foster (2007) es uno de los indicadores utilizados en la actualidad para operacionalizar la pobreza desde el enfoque de capacidades. Sin embargo, el IPM no dispone aún de suficientes datos para realizar un análisis histórico de dos décadas (1990-2010) para la totalidad de países considerados en este artículo.

En este trabajo se utilizan dos indicadores de privaciones individuales para presentar una realidad tridimensional de la pobreza desde el enfoque de capacidades que sí permiten realizar un análisis temporal. El primero presenta la pobreza desde la capacidad de salud y estudia la privación de alimentación nutritiva. El segundo presenta la pobreza desde la capacidad de calidad de vida y estudia la privación al acceso de agua potable y a los servicios de saneamiento. En ambos casos, se considera a la población en pobreza como la proporción de población incapaz a acceder a los servicios/bienes básicos respectivos y, siguiendo el enfoque de capacidades de Sen, se plantea que a mayor satisfacción de necesidades básicas - mayor nutrición y acceso a agua potable e infraestructuras sanitarias, entre otros - menor será el nivel de pobreza. Estos

manera: tener una bicicleta le brinda la oportunidad a un individuo de trasladarse, que de otra manera seria imposible que lo hiciera. Así, la funcionalidad (característica) de transporte de la bicicleta le otorga al individuo una capacidad de movimiento. Esa capacidad le brinda a este individuo una utilidad o felicidad si esta posibilidad de trasladarse es vista como una necesidad o lo encuentra al menos placentero. 
indicadores presentan una parte de las dimensiones y privaciones que puede sufrir un individuo en pobreza - mas no la totalidad de las mismas - , por tal razón este trabajo se refiere a pobreza de capacidades y no a pobreza multidimensional.

\section{a) Indicador de pobreza de capacidades 1 (PC1): Insuficiencia alimentaria ${ }^{7}$}

Con el propósito de presentar la capacidad de salud en esta investigación se utiliza un indicador referido a la proporción de población con insuficiencia alimentaria. Así se presume que un individuo que sea incapaz de ingerir unos alimentos nutritivos a diario, carecerá de unas capacidades básicas que permitan el desarrollo de capacidades avanzadas como el bienestar y la libertad.

Se ha utilizado el indicador de insuficiencia alimentaria en lugar del de población desnutrida porque es más útil en términos estadísticos ${ }^{8}$. En el informe de la FAO et al. (2013) se define la insuficiencia alimentaria como la proporción de la población que se encuentra en riesgo de alcanzar los requisitos alimentarios asociados con una actividad física normal. Por lo tanto, incluye aquellos individuos que, si bien no pueden ser considerados como crónicamente desnutridos, se encuentran condicionados por insuficiencia alimentaria.

¿Por qué este indicador es útil para mostrar la salud desde el enfoque de las capacidades? Alkire y Santos (2010: 14) mencionan que "la desnutrición es un indicador directo del funcionamiento vital. La malnutrición en los niños puede tener efectos negativos para toda la vida de un individuo en términos de su desarrollo cognitivo y físico. Los adultos o niños que estén desnutridos también son susceptibles de otros desordenes en salud, son menos aptos para aprender y concentrarse y su rendimiento en el trabajo puede no ser el mejor".

\section{b) Indicador de pobreza de capacidades 2 (PC2): incapacidad de acceso a fuentes mejoradas agua potable e infraestructuras sanitarias}

El IPM y el Índice de Desarrollo Humano (IDH) consideran la calidad de vida como una de las dimensiones cruciales en el bienestar de un individuo. A diferencia del IDH, que desde 2010 utiliza el indicador monetarista del "ingreso neto nacional en paridad

${ }^{7}$ Se refiere al termino anglosajón "prevalence of food inadequacy".

${ }^{8}$ En la base de datos de la FAO no se presentan cifras de desnutrición ni de insuficiencia alimentaria inferiores al umbral del 5\%. En una cantidad considerable de los casos de la muestra los datos del indicador proporción de población en desnutrición son inferiores a 5\% por lo que la base de datos no refleja el número exacto de carencia alimentaria haciendo que el análisis relacional no sea efectivo. Sin embargo y debido a que el umbral de nutrición en el indicador de insuficiencia alimentaria presenta un valor calórico más elevado, el número de los casos que presentan un valor inferior a $5 \%$ de insuficiencia alimentaria se ve reducido considerablemente. Por lo tanto, este indicador es más útil para el análisis relacional ya que presenta una mayor cantidad de valores reales de carencia alimentaria que el primer indicador. 
de poder adquisitivo", el IPM utiliza seis indicadores 9 para medir la calidad de vida. Debido a la escasez de datos no fue posible considerar los seis indicadores para los 21 países de la muestra durante las dos décadas que son consideradas en este estudio. Por lo tanto en este trabajo se han seleccionado los indicadores de acceso a agua potable y acceso a servicios de saneamiento como representantes del grupo de indicadores de calidad de vida ${ }^{10}$. Para facilitar el análisis relacional los dos indicadores fueron transformados en un índice compuesto por medio de su media aritmética ${ }^{11}$.

Según la FAO (2013) el acceso razonable a agua potable se refiere a la proporción de la población que dispone de una cantidad adecuada de agua potable proveniente de una fuente mejorada como conexión en el domicilio, fuente publica, pozo protegido o mediante le recolección de agua de lluvia ${ }^{12}$. La FAO (2013) también se refiere al acceso a servicios mejorados de saneamiento como la proporción de la población con al menos un acceso adecuado a servicio de alcantarillado ${ }^{13} \cdot{ }^{14}$

Alkire y Santos (2010: 16) defienden estos indicadores como aptos para representar la variable calidad de vida. Ellas son conscientes de que los indicadores de calidad de vida son medios más que fines y que, por lo tanto, no son medidas directas de funcionalidades. Sin embargo consideran que estos indicadores tienen un punto fuerte: “(...) a diferencia de los ingresos monetarios, que pueden servir para una gran cantidad de propósitos - y uno nunca sabe si es utilizado efectivamente para lograr las necesidades consideradas como básicas-, estos [dos indicadores] son medios estrechamente relacionados con los fines o funcionalidades que deben facilitar. El acceso a agua potable sirve directamente para satisfacer las necesidades de hidratación e higiene y la higiene también se ve facilitada por el acceso a un servicio de saneamiento".

${ }^{9}$ Acceso a infraestructuras de saneamiento, acceso a fuentes mejoradas de agua potable, acceso a electricidad en el hogar, piso de la vivienda adecuado, combustible para cocinar y propiedad de bienes básicos.

${ }^{10}$ Este indicador también formó parte de los Objetivos de Desarrollo del Milenio (ODM), específicamente la meta 7C. Ver Cruz-Martínez (2015) para un análisis alternativo del 'éxito' de los ODM en América Latina y el Caribe, tomando en consideración la meta 7C y la meta 1A.

11 Formula $=\frac{\text { Incapacidad de acceso a agua potable }+ \text { Incapacidad de acceso } a \text { Sanitarios }}{2}$

${ }^{12}$ Un acceso razonable es definido como la disponibilidad de al menos 20 litros de agua por persona al día, de una fuente mejorada dentro de un kilómetro de la vivienda del individuo considerado.

${ }^{13}$ Serán infraestructuras mejoradas aquellas que sean capaces de prevenir el contacto humano, animal y de insectos con la excreta.

${ }^{14}$ Para una mayor información sobre la metodología utilizada para construir y recolectar estos indicadores dirigirse a: $<$ http://www.wssinfo.org/definitions-methods/introduction/>. 


\section{Resultados}

A continuación se presentan los resultados de las regresiones entre el gasto social per cápita y los cuatro indicadores de pobreza fijados desde el enfoque monetario y de capacidades. El análisis está orientado a la contestación de las preguntas esbozadas en el diseño de investigación.

\subsection{Regresión lineal entre gasto social per cápita y pobreza: promedio de 1990-2010}

La primera de las tres técnicas de investigación que se ha utilizado para medir la relación entre gasto social per cápita y pobreza fue una regresión lineal ajustada por mínimos cuadrados. La fórmula del modelo de regresión lineal es: $Y=\beta X+A$; donde $\mathrm{Y}$ es el nivel de pobreza, $\mathrm{X}$ el gasto social per cápita, $\mathrm{A}$ es el intercepto en $\mathrm{Y}, \mathrm{y} \beta$ representa el coeficiente de regresión. Se realizaron cuatro regresiones, una por cada indicador de pobreza. Por medio de esta técnica se buscó dar respuesta a la siguiente pregunta. ¿Qué fortaleza presenta la relación entre el esfuerzo de bienestar y el nivel de pobreza en América Latina y el Caribe?

En la Figura 1 se observan cuatro gráficos con el análisis de regresión entre el gasto social per cápita y los cuatro indicadores de pobreza respectivos. En el análisis se incluyeron hasta 21 países de la región de América Latina y el Caribe — siempre que los datos estuvieran disponibles $-{ }^{15}$. Para el modelo de regresión con la variable dependiente PM1 y PM2 hay 18 casos, mientras que con la variable PC1 y PC2 hay 21 casos. Ahora bien, ¿cómo es la relación entre el gasto social per cápita y los cuatro indicadores de pobreza?

La inclinación de la recta de regresión lineal en los cuatro gráficos de la Figura 1 confirma que existe una relación negativa entre las variables gasto social per cápita y pobreza. En los cuatro modelos el valor del coeficiente de regresión $(\beta)$ es negativo, lo que confirma la existencia de la relación negativa observada en los gráficos. Mediante el coeficiente de correlación (R) es posible cuantificar el grado de relación existente entre las variables. Los resultados del $\mathrm{R}$ entre gasto social per cápita y las medidas de pobreza fueron: PM1 $(0,87)$; PM2 $(0,48)$; PC1 $(0,82)$; PC2 $(0,79)$.

Además se calculó el coeficiente de determinación $\left(\mathrm{R}^{2}\right)$ con el propósito de presentar la calidad del ajuste obtenido en el análisis de regresión. Etxeberria (1999: 20) indica que el objetivo principal de la regresión es explicar los cambios que ocurren en la

${ }^{15}$ Estos son: Argentina, Bolivia, Brasil, Chile, Colombia, Costa Rica, Cuba, Ecuador, El Salvador, Guatemala, Honduras, Jamaica, México, Nicaragua, Panamá, Paraguay, Perú, República Dominicana, Trinidad y Tobago, Uruguay, y Venezuela. No hay datos disponibles para los casos de Trinidad y Tobago, Cuba ni Jamaica para los indicadores PM1 y PM2. 
variable dependiente, y que pueden ser explicados por los cambios que también ocurren en la variable explicativa. Por ello cuanto mayor sea el coeficiente de determinación mayor será el porcentaje de cambios explicados por el modelo. En este estudio el coeficiente de determinación permite cuantificar el porcentaje de cambios que se dan en la pobreza, y que son explicados por los cambios que se dan en el gasto social per cápita.

FiguRA 1: REgResión LINEAL POR MÍNIMOS CUADRADOS ENTRE GASTO SOCIAL PER CÁPITA Y POBREZA DESDE El ENFOQUE MONETARIO (PM1, PC2) y DE CAPACIDADES (PC1, PC2) en América Latina y el Caribe Para el Periodo temporal 1990-2010

PM1

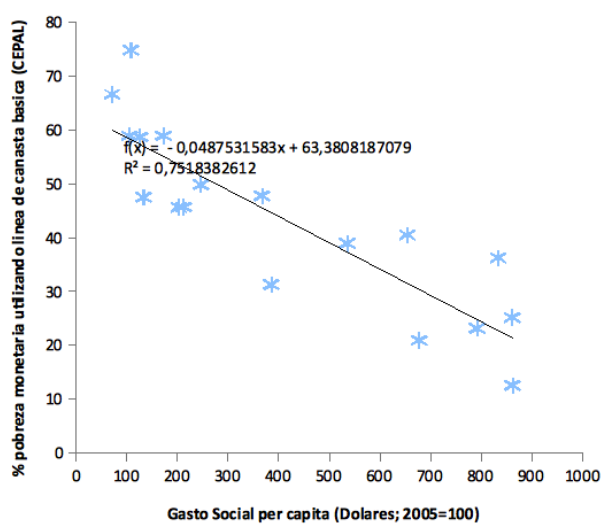

PM2

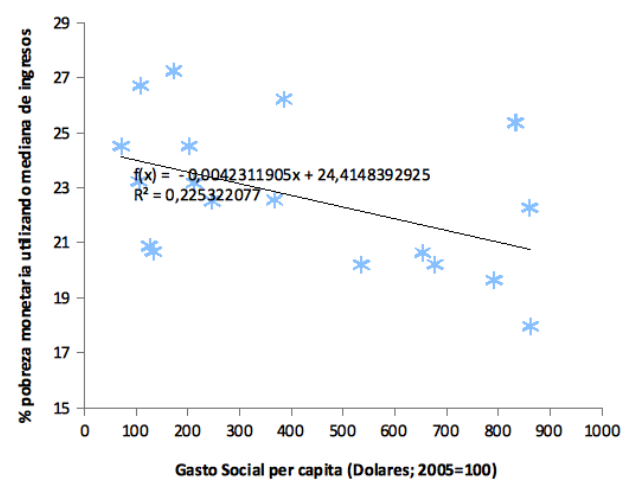

PC1

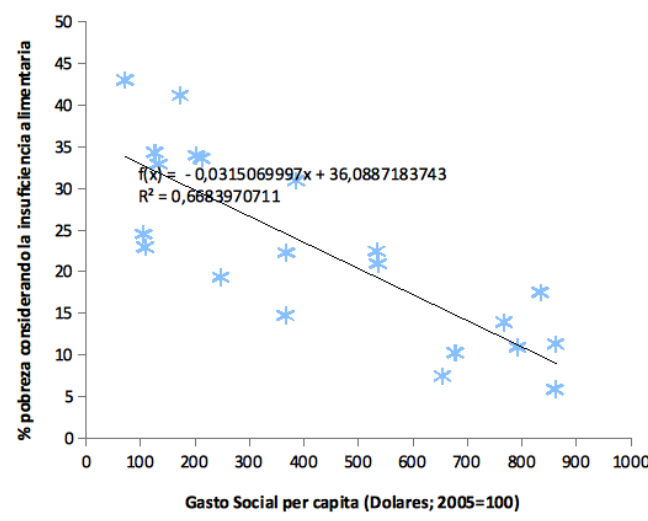

PC2

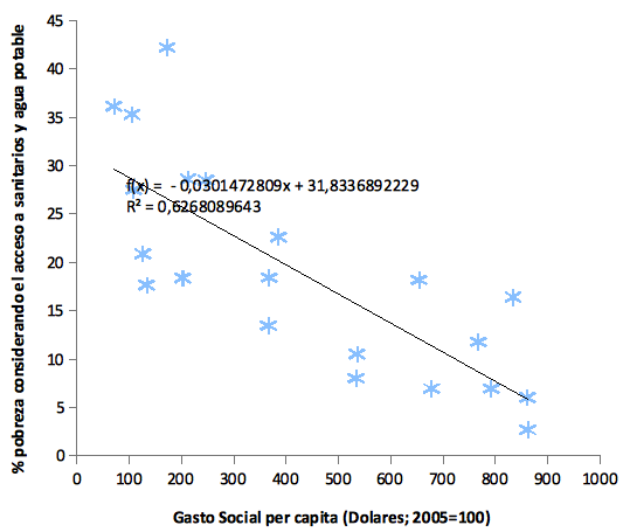

Notas:

1. La pobreza monetaria (PM1 y PM2) de Argentina hace referencia a la zona urbana, el resto de los casos hace referencia a la pobreza nacional. 2. En la parte superior del eje de Y se hace mención de la variable dependiente utilizada para el respectivo análisis.

Fuente: Elaboración propia; CEPAL (s/f); FAO (2013). 
Los resultados del $\mathrm{R}^{2}$ para las cuatro regresiones realizadas se encuentran en la Figura 1. Tres de los cuatro modelos de regresión presentaron un coeficiente de determinación superior a 0,60 mientras que el modelo que consideró la PM2 como variable dependiente obtuvo solo un 0,23 . Los resultados denotan que cerca de un $75,18 \%$ de la varianza de la PM1, $22,53 \%$ de la varianza de la PM2, 66,84\% de la varianza de la PC1 y $62,68 \%$ de la varianza de la PC2 pueden ser explicados por el gasto social per cápita en sus respectivos modelos.

El R ${ }^{2}$ ajustado suele ser menor que el coeficiente de determinación, debido a que se utiliza para compensar la adición de variables independientes en el modelo ${ }^{16}$. Los resultados del $\mathrm{R}^{2}$ ajustado fueron superiores a 0,60 en tres de las cuatro regresiones, mientras que el modelo que considero la PM2 como variable dependiente obtuvo solo un 0,18.

Una vez calculados los coeficientes y la recta de regresión será imprescindible verificar si efectivamente el modelo de regresión obtenido podría ser considerado como nulo. Para esto se ha realizado un análisis de contraste de regresión. Mediante el contraste de regresión se asignó una medida de probabilidad a la hipótesis nula: $\mathrm{H}_{\mathrm{o}}=>\mathrm{b}=0$. De confirmarse la hipótesis nula, esto significará que el conocimiento de la variable independiente $(\mathrm{X})$ de los países latinoamericanos no va a proporcionar más información respecto de sus niveles nacionales de pobreza $(\mathrm{Y})$ que el conocimiento de la media de la variable dependiente. Rojo Abuín (2007: 15) considera que "en general, si el p-value es menor de 0,05 se acepta que el modelo de regresión es significativo; en caso contrario no podemos hablar de regresión pues el modelo sería nulo". También se puede hablar de un modelo de regresión aún más significativo si el $p$-value es menor de 0,01 .

Utilizando el análisis de contraste de regresión se confirmó que el $p$-value es menor de 0,01 para los modelos que utilizaron la variable dependiente PM1, PC1 y PC2, mientras que para el modelo que utilizó la variable dependiente PM2 el $p$-value fue menor de 0,05 . Por lo tanto se concluye que es muy poco probable que estos datos presenten un valor de $b=0$ y a su vez se confirma que el modelo de regresión con PM2 es significativo y el modelo de regresión con PM1, PC1 y PC2 es altamente significativo. Es decir que existe una alta correlación entre el gasto social per cápita y el nivel de pobreza, ya que en tres de las cuatro indicadores de pobreza los cambios en la variable independiente explican gran parte de los cambios que ocurren en la variable dependiente. Utilizando el promedio de resultados en la muestra de la región latinoamericana para el periodo 1990-2010, se puede confirmar que existe una tendencia de que a mayor gasto social per cápita menor nivel de pobreza monetaria y de capacidades ${ }^{17}$. Los modelos con el PM1, PC1 y PC2 confirman estos resultados.

${ }^{16}$ Esto quiere decir que $\mathrm{R}^{2}$ ajustado, generalmente aumentará a medida que se consideren otras variables independientes, pero nunca disminuirá en valor (Crewson, 2006).

${ }^{17}$ Considero necesario recalcar que en esta investigación solo se incluyen dos de las muchas capacidades necesarias para que un individuo no sea considerado en pobreza. Así que nos referimos a una pobreza desde la capacidad de calidad de vida y de salud. 


\subsection{Inclusión de controles a la regresión lineal múltiple entre gasto social per cápita y pobreza en 5 tiempos $(1990,1995,2000,2005,2010)$}

La segunda de las tres técnicas de investigación que se utilizó para medir la relación entre gasto social per cápita y pobreza, desde el enfoque monetarista y de capacidades, fue una regresión lineal múltiple ajustada por mínimos cuadrados. Las dos principales diferencias entre esta segunda técnica y la anterior es que se incluyeron tres indicadores que ejercen como controles - por lo que es una regresión múltiple - y que se realizaron regresiones en 5 tiempos $(1990,1995,2000,2005,2010)$ en cada uno de los cuatro modelos. La fórmula del modelo de regresión lineal es: $Y=\beta X 1+\alpha X 2+\delta X 3+\varepsilon X 4+A$; donde $\mathrm{Y}$ es el nivel de pobreza (PM1, PM2, PC1, PC2), X1 el gasto social per cápita, X2 el porcentaje de población mayor de 65 años de edad, X3 el porcentaje de población desempleada, X4 el PIB per cápita, A es el intercepto en $\mathrm{Y}$, a la vez que $\beta, \alpha, \delta, \varepsilon$ representan los coeficientes de regresión. Por medio de esta técnica se buscó dar respuesta a las siguientes dos preguntas. ¿La relación entre las variable dependiente y explicativa mantiene su fortaleza en distintos momentos del periodo temporal considerado en esta investigación (1990-2010)? ¿La relación entre las variables mantiene su fortaleza y facultades explicativas, al incorporar controles en el modelo de regresión?

En la Tabla 1 se presentan los resultados de las regresiones realizadas utilizando la técnica 2 para los cinco periodos establecidos. En el análisis se incluyeron hasta 21 países de la región - siempre que los datos estuvieran disponibles-. En los cuatro modelos para 1990, 1995, 2000, 2005 y 2010 el valor del coeficiente de regresión de la variable explicativa es negativo, con la excepción del modelo con la variable dependiente PM2. Esto confirma que la relación entre el gasto social per cápita y la pobreza monetaria (PM1) y de capacidades (PC1 y PC2) es negativa en los cinco tiempos, es decir que existe una tendencia de que a mayor gasto social menor nivel de pobreza ${ }^{18}$.

Los resultados del coeficiente de correlación (R) entre gasto social per cápita y las medidas de pobreza fueron superiores a 0,70 con la excepción del modelo con PM2 para los años 2000, 2005 y 2010. Los resultados del coeficiente de determinación $\left(\mathrm{R}^{2}\right)$ fueron superiores a 0,58 en las cuatro regresiones realizadas en los cinco periodos temporales, nuevamente con la excepción del modelo que consideró la PM2 como variable dependiente en los años 2000, 2005 y 2010. Los resultados denotan que sobre un $85 \%$

${ }^{18}$ Ahora bien, ¿por qué el modelo con la PM2 no presentó una relación negativa? Para dar respuesta a esta interrogante sería necesario realizar una investigación más exhaustiva, pero se podría considerar que para observar disminuciones de la PM2 sería necesario que el gasto social per cápita elevara los ingresos de la población en pobreza por encima de la brecha del 50\% de la mediana de ingresos. Un defensor de la pobreza desde el enfoque monetarista utilizaría estos resultados para evidenciar la necesidad de programas monetarios focalizados a la población en pobreza monetaria. Sin embargo, debido a que este indicador presenta un componente de la desigualdad no basta con solo asignar transferencias monetarias focalizadas. Sino que es necesario prestar atención a la redistribución y corregir la desigualdad de ingresos. 
de la varianza de la PM1, 25\% de la varianza de la PM2 $2^{19}, 58 \%$ de la varianza de la PC1 y $60 \%$ de la varianza de la PC2, puede ser explicada por los respectivos modelos con gasto social per cápita como variable explicativa y controlando para factores demográficos y cíclicos. Los resultados del $\mathrm{R}^{2}$ ajustado fueron superiores a 0,47 en la totalidad de los modelos a excepción del modelo con PM2 en los años 2000, 2005 y 2010.

Utilizando el análisis de contraste de regresión se confirmó que el $p$-value es menor de 0,01 para los modelos que utilizaron la variable dependiente PM1 (1995, 2000, 2005, 2010), PC1 (1990-2010) y PC2 (1990-2010), mientras que para el modelo que utilizó la variable dependiente PM2 (1995) y PM1 (1990) el p-value fue menor de 0,05. Por lo tanto se concluye que es muy poco probable que estos datos presenten un valor de $b=0$ y a su vez se confirma que el modelo de regresión con indicadores de pobreza desde el enfoque de capacidades es más significativo que el modelo de regresión con indicadores de pobreza monetaria. El modelo con la variable dependiente PM2 no fue significativo para los años 1990, 2000, 2005 ni 2010.

El gasto social per cápita aparenta ser importante para explicar diferencias en los niveles de pobreza con un $95 \%$ de confianza entre los países de la muestra solo para el año 1995 con el modelo PM2, para el 2005 con el modelo PC1 y para el 2010 con el modelo PC1. La variable población en edad avanzada no fue significativa en ninguno de los modelos, mientras que la variable población desempleada solo fue significativa $(0,05)$ para el año 1995 con el modelo PC1. Por último, la variable control PIB per cápita fue más significativa para explicar las diferencias en los niveles de pobreza monetaria y de capacidades que la propia variable explicativa del análisis. El PIB per cápita presentó valores significativos al nivel 0,05 en el año 1990 (PC1, PM2) y 2000 (PC2), además de presentar valores significativos en un nivel 0,01 para el año 1995 (PC1, PC2, PM2) y 2005 (PM1).

$\mathrm{Al}$ incorporar controles al modelo de regresión el gasto social per cápita pierde facultades explicativas para presentar por si solo las diferencias de pobreza de los países de la muestra en los cinco periodos evaluados. Sin embargo los modelos PC1, PC2 y PM1 presentaron valores del coeficiente de correlación y determinación elevados para los 5 periodos temporales, por lo que se puede considerar que la relación entre las variables dependiente y explicativa mantiene su fortaleza en los distintos momentos del periodo temporal considerando los tres controles.

${ }^{19}$ Para 1990 y 1995 sobre el 70\% de la varianza de la PM2 era explicada por el modelo. 
TABLA 1: REGRESIÓN LINEAL POR MÍNIMOS CUADRADOS ENTRE GASTO SOCIAL PER CÁPITA Y POBREZA DESDE El ENFOQUe MONETARIO (PM1, PC2) y DE CAPACIDADES (PC1, PC2) en América Latina y el CARibe alrededor de 1990, 1995, 2000, 2005 y 2010 TOMANDO EN CONSIDERACIÓN FACTORES CÍCLICOS Y DEMOGRÁFICOS

\begin{tabular}{|c|c|c|c|c|c|c|c|c|}
\hline & \multicolumn{4}{|c|}{1990} & \multicolumn{4}{|c|}{1995} \\
\hline & PC1 & $\mathrm{PC} 2$ & PM1 & PM2 & $\mathrm{PC} 1$ & $\mathrm{PC} 2$ & PM1 & PM2 \\
\hline \multirow[t]{2}{*}{ Gasto Social per cápita } & $-0,002$ & $-0,021$ & $-0,029$ & 0,007 & $-0,007$ & $-0,013$ & $-0,015$ & $0,010^{* *}$ \\
\hline & $(-0,104)$ & $(-1,536)$ & $(-1,375)$ & $(-1,610)$ & $(-0,664)$ & $(-1,414)$ & $(-0,944)$ & $(-2,32)$ \\
\hline \multirow[t]{2}{*}{$\begin{array}{l}\text { Población sobre } 65 \\
\text { años de edad (\%) }\end{array}$} & -1.685 & -1.222 & -6.550 & $-0,770$ & $-0,896$ & $-0,601$ & -4.979 & $-0,500$ \\
\hline & $(-1,189)$ & $(-0,925)$ & $(-1,483)$ & $(-1,567)$ & $(-0,769)$ & $(-0,565)$ & $(-1,957)$ & $(-0,757)$ \\
\hline \multirow[t]{2}{*}{ Desempleo (\%) } & $-0,853$ & $-0,613$ & -1.775 & $-0,479$ & $0,935 * *$ & $-0,242$ & 0,208 & $-0,001$ \\
\hline & $(-1,957)$ & $(-1,507)$ & $(-1,333)$ & $(-1,610)$ & $(-2,498)$ & $(-0,708)$ & $(-0,322)$ & $(-0,008)$ \\
\hline \multirow[t]{2}{*}{ PIB per cápita } & $-0,005 * *$ & $-0,002$ & $-0,005$ & $-0,002 * *$ & $-0,004 *$ & $-0,003^{*}$ & $-0,004$ & $-0,002 *$ \\
\hline & $(-2,813)$ & $(-1,337)$ & $(-2,138)$ & $(-3,275)$ & $(-3,429)$ & $(-3,307)$ & $(-1,656)$ & $(-3,817)$ \\
\hline \multirow[t]{2}{*}{ Intercepto en $\mathrm{Y}$} & $-47,127^{*}$ & $51,965^{*}$ & $124,44^{*}$ & $35,316^{*}$ & $43,028^{*}$ & $49,544^{*}$ & $93,623^{*}$ & $32,617 *$ \\
\hline & $-(6,079)$ & $(-7,190)$ & $(-6,109)$ & $(-8,611)$ & $(-7,578)$ & $(-9,560)$ & $(-8,847)$ & $(-11,865)$ \\
\hline $\mathrm{R}$ & 0,807 & 0,812 & 0,941 & 0,876 & 0,841 & 0,882 & 0,933 & 0,842 \\
\hline R2 & 0,652 & 0,66 & 0,886 & 0,768 & 0,706 & 0,777 & 0,871 & 0,709 \\
\hline R2 Ajustado & 0,559 & 0,569 & 0,773 & 0,535 & 0,633 & 0,722 & 0,806 & 0,564 \\
\hline Prueba F & $7,025^{*}$ & $7,267 *$ & $7,802 * *$ & 3.302 & $9,628^{*}$ & $13,971^{*}$ & $13,472^{*}$ & $4,875^{* *}$ \\
\hline \multirow[t]{2}{*}{$\mathrm{N}$} & 20 & 20 & 9 & 9 & 21 & 21 & 13 & 13 \\
\hline & \multicolumn{4}{|c|}{2000} & \multicolumn{4}{|c|}{2005} \\
\hline \multirow[t]{2}{*}{ Gasto Social per cápita } & $-0,013$ & $-0,013$ & $-0,022$ & 0,003 & $-0,019 * *$ & $-0,008$ & $-0,010$ & 0,001 \\
\hline & $(-1,379)$ & $(-1,719)$ & $(-2,184)$ & $(-0,797)$ & $(-2,166)$ & $(-1,118)$ & $(-1,072)$ & $(-0,178)$ \\
\hline \multirow[t]{2}{*}{$\begin{array}{l}\text { Población sobre } 65 \\
\text { años de edad (\%) }\end{array}$} & -1.749 & $-0,811$ & -1.909 & 0,068 & $-0,938$ & -1.221 & -1.676 & $-0,430$ \\
\hline & $(-1,529)$ & $(-0,948)$ & $(-1,024)$ & $(-0,089)$ & $(-0,848)$ & $(-1,405)$ & $(-1,623)$ & $(-0,951)$ \\
\hline \multirow[t]{2}{*}{ Desempleo (\%) } & 0,573 & $-0,361$ & $-0,115$ & 0,016 & 0,026 & $-0,324$ & $-0,085$ & 0,145 \\
\hline & $(-1,229)$ & $(-1,035)$ & $(-0,246)$ & $(-0,085)$ & $(-0,051)$ & $(-0,807)$ & $(-0,169)$ & $(-0,663)$ \\
\hline \multirow[t]{2}{*}{ PIB per cápita } & $-0,001$ & $-0,002 * *$ & $-0,003$ & $-0,001$ & 0,0004 & $-0,001$ & $-0,003 *$ & $-0,0004$ \\
\hline & $(-1,002)$ & $(-2,330)$ & $(-1,974)$ & $(-1,929)$ & $(-0,663)$ & $(-1,292)$ & $(-3,017)$ & $(-0,906)$ \\
\hline \multirow[t]{2}{*}{ Intercepto en Y } & $38,846^{*}$ & $42,984 *$ & $80,994 *$ & $27,232^{*}$ & $33,629^{*}$ & $35,798^{*}$ & $79,118^{*}$ & $26,696^{*}$ \\
\hline & $(-5,625)$ & $(-8,330)$ & $(-9,331)$ & $(-7,608)$ & $(-4,847)$ & $(-6,572)$ & $(-11,720)$ & $(-9,042)$ \\
\hline $\mathrm{R}$ & 0,798 & 0,871 & 0,923 & 0,534 & 0,762 & 0,807 & 0,923 & 0,507 \\
\hline R2 & 0,637 & 0,759 & 0,851 & 0,285 & 0,581 & 0,651 & 0,853 & 0,257 \\
\hline R2 Ajustado & 0,541 & 0,694 & 0,797 & 0,026 & 0,477 & 0,564 & 0,807 & 0,029 \\
\hline Prueba F & $6,591 *$ & $11,791^{*}$ & $15,755^{*}$ & 1.099 & $5,553 *$ & $7,465^{*}$ & $18,790^{*}$ & 1.125 \\
\hline $\mathrm{N}$ & 20 & 20 & 16 & 16 & 21 & 21 & 18 & 18 \\
\hline
\end{tabular}




\begin{tabular}{lcccc}
\hline & \multicolumn{4}{c}{2010} \\
\hline & PC1 & PC2 & PM1 & PM2 \\
\hline Gasto Social per cápita & $-0,018^{* *}$ & $-0,005$ & $-0,015$ & 0,002 \\
& $(-2,632)$ & $(-0,762)$ & $(-1,974)$ & $(-0,538)$ \\
Población sobre 65 & 0,406 & $-0,801$ & -1.201 & $-0,497$ \\
años de edad (\%) & & & & \\
& $(-0,393)$ & $(-0,868)$ & $(-1,066)$ & $(-1,070)$ \\
Desempleo (\%) & $-0,883$ & $-0,034$ & $-0,042$ & 0,330 \\
& $(-1,341)$ & $(-0,057)$ & $(-0,046)$ & $(-0,876)$ \\
PIB per cápita & 0,0005 & $-0,001$ & $-0,002$ & $-0,0004$ \\
& $(-0,802)$ & $(-1,102)$ & $(-1,952)$ & $(-1,219)$ \\
Intercepto en Y & $32,197 *$ & $28,926^{*}$ & $69,085^{*}$ & $25,184^{*}$ \\
& $(-4,392)$ & $(-4,411)$ & $(-7,840)$ & $(-6,931)$ \\
& & & & \\
R & 0,770 & 0,779 & 0,939 & 0,637 \\
R2 & 0,593 & 0,606 & 0,882 & 0,406 \\
R2 Ajustado & 0,491 & 0,508 & 0,842 & 0,208 \\
Prueba F & $5,831 *$ & $6,157^{*}$ & $22,343^{*}$ & 2.054 \\
\hline $\mathrm{N}$ & 21 & 20 & 17 & 17 \\
\hline
\end{tabular}

Notas:

Estadísticas t en paréntesis

La pobreza monetaria (PM1 y PM2) de Argentina hace referencia a la zona urbana, el resto de los casos hace referencia a la pobreza nacional. Datos no disponibles para PM1, PM2, PC1 ni PC2: Bolivia 1990, Honduras 2000. Dato no disponible para PM1 ni PM2: Cuba 1990-2010, El Salvador 1990-1995, Jamaica 1990-2010, Panamá 1990-1995, Paraguay 1990-1995, Perú 1990, Republica Dominicana 1990-1995, Trinidad y Tobago 1990-2010, Uruguay 1990-2000. Dato no disponible para PM1: Ecuador 1990-1995. Dato no disponible para PM2: Nicaragua 1990.

* Significación estadística en 0,01

** Significación estadística en 0,05

Fuente: Elaboración propia; FAO (2013); CEPAL (s/f); Heston et al. (2012); World Health Organization and United Nations Children's Fund (s/f); Banco Interamericano de Desarrollo (2014) y cálculos propios.

\subsection{Regresión lineal por mínimos cuadrados con los errores estándares de paneles corregidos: análisis transnacional de series de tiempo combinadas}

En la tercera de las técnicas de investigación se realizó un análisis transnacional de series de tiempo combinadas. Se colocaron los resultados de la variable dependiente, explicativa y controles de todos los países para los años 1990, 1995, 2000, 2005 y 2010 en una serie de tiempo. A esa serie temporal combinada se le realizaron dos modelos de análisis de regresión: el primero fue una regresión lineal por mínimos cuadrados con los errores estándares de los paneles corregidos - PCSE por sus siglas en inglés-y el segundo fue un modelo de efectos fijos utilizando una regresión lineal por mínimos 
cuadrados y los años como variable ficticia (binaria) con los errores estándares de los paneles corregidos - LSDV por sus siglas en ingles $-{ }^{20}$.

Las principales diferencias entre esta tercera técnica y la segunda es que en vez de realizar regresiones en 5 tiempos se realiza una regresión para la serie temporal transnacional, y además se corrigen los errores estándares de los modelos lineales siguiendo a Beck y Katz (1995) por medio de la función pcse de Bailey y Katz (2011) en el programa estadístico R. Según Bailey y Katz (2011: 1) los datos en el análisis transnacional de series temporales presentan usualmente correlaciones contemporáneas entre las unidades (países) y niveles unitarios de heteroscedasticidad produciendo errores estándares incorrectos en las regresiones lineales por mínimos cuadrados. Los errores estándares provenientes de los mínimos cuadrados se corrigen por medio de un estimador de la matriz de covarianzas de los parámetros estimados, que Beck y Katz (1995) llamaron errores estándares de los paneles corregidos ("panel corrected standard errors") ${ }^{21}$.

$\mathrm{La}$ fórmula de los modelos de regresión lineal utilizados fue: $Y_{p t}=\beta X 1_{p t}+\alpha X 2_{p t}+\delta X 3_{p t}+\varepsilon X 4_{p t}+A$; donde Y es el nivel de pobreza (PM1, $\mathrm{PM} 2, \mathrm{PC} 1, \mathrm{PC} 2)$ del país $p$ en el periodo $t, \mathrm{X} 1$ el gasto social per cápita del país $p$ en el periodo $t, \mathrm{X} 2$ el porcentaje de población mayor de 65 años de edad del país $p$ en el periodo $t, \mathrm{X} 3$ el porcentaje de población desempleada del país $p$ en el periodo $t, \mathrm{X} 4$ el PIB per cápita del país $p$ en el periodo $t$, A es el intercepto en Y, a la vez que $\beta, \alpha, \delta$, $\varepsilon$ representan los respectivos coeficientes de regresión.

Por medio de esta técnica se buscó dar respuesta a la siguiente pregunta: ¿La relación entre las variables mantiene su fortaleza y facultades explicativas, al incorporar controles en el modelo de regresión en el periodo 1990-2010?

En la Tabla 2 se observan los resultados de la regresión lineal por mínimos cuadrados y errores estándares de paneles corregidos a la serie temporal (1990-2010) con hasta 21 países de la región latinoamericana y caribeña. Al igual que con la técnica 2, se incorporan al análisis tres controles demográficos y cíclicos. La utilización de la base de datos temporal aumentó considerablemente los grados de libertad del análisis en comparación con la técnica 1 y 2 [N x T = 72 (PM1); 73 (PM2); 103 (PC1 y PC2)].

Los coeficientes del gasto social $(\beta i$ ) presentaron valores negativos - para ambos modelos - en las regresiones con la variable dependiente de PM1, PC1 y PC2. Al igual que con la técnica 2, la regresión entre PM2 y el gasto social per cápita no fue negativa en ninguno de los dos modelos utilizados. Esto confirma nuevamente que la relación entre el gasto social per cápita y la pobreza monetaria (PM1) y de capacidades (PC1 y PC2) es negativa, es decir se confirma una tendencia de que a mayor gasto social es de esperarse

20 "Fixed effects using least square dummy variable model".

${ }^{21}$ Beck y Katz (1995) evidencian en su artículo la utilidad de las regresiones por mínimos cuadrados para los análisis transnacionales de series temporales, por encima de las regresiones por mínimos cuadrados generalizados factibles (FGLS) propuestos por Parks (1967) y popularizados por Kmenta (1986). 
un menor nivel de pobreza. Vale la pena resaltar que la totalidad de coeficientes en las regresiones realizadas en la técnica 3 para los controles población mayor de 65 años y PIB per cápita fueron negativos. Es decir que también existe una tendencia de que a mayor población en edad avanzada y PIB per cápita menor será el nivel de pobreza. Mientras que el coeficiente de regresión del control desempleo con variable dependiente PM1 y PC2 es negativo, y las regresiones con PM2 y PC1 presentaron coeficientes positivos.

\section{TABLA 2: REGRESIÓN LINEAL POR MÍNIMOS CUADRADOS CON ERRORES ESTÁNDARES CORREGIDOS (PCSE) ENTRE GASTO SOCIAL PER CÁPITA Y POBREZA DESDE EL ENFOQUE MONETARIO (PM1, PC2) Y DE CAPACIDADES (PC1, PC2) A UNA SERIE TEMPORAL TRANSNACIO- nal de Series de tiempo combinada en América Latina y el Caribe, tomando EN CONSIDERACIÓN FACTORES CÍCLICOS Y DEMOGRÁFICOS}

\begin{tabular}{lccccccccc}
\hline & \multicolumn{2}{c}{ PM1 } & \multicolumn{2}{c}{ PM2 } & \multicolumn{2}{c}{ PC1 } & \multicolumn{2}{c}{ PC2 } \\
& Modelo 1 & Modelo 2 & Modelo 1 & Modelo 2 & Modelo 1 & Modelo 2 & Modelo 1 & Modelo 2 \\
\hline $\begin{array}{l}\text { Gasto Social } \\
\text { per cápita }\end{array}$ & $-0,021^{*}$ & $-0,018^{*}$ & 0,002 & 0,003 & $-0,011^{* *}$ & $-0,011^{* *}$ & $-0,008^{* *}$ & $-0,008^{* *}$ \\
& $(0,003)$ & $(0,003)$ & $(0,001)$ & $(0,001)$ & $(0,003)$ & $(0,003)$ & $(0,003)$ & $(0,003)$ \\
\hline $\begin{array}{l}\text { Población sobre 65 } \\
\text { años de edad (\%) }\end{array}$ & $-1,627^{* *}$ & $-1,810^{* *}$ & $-0,391$ & $-0,480^{* *}$ & $-1,345^{* *}$ & $-1,376^{* *}$ & $-1,408^{* *}$ & $-1,374^{*}$ \\
& & & & & & & & \\
\hline & $(0,465)$ & $(0,508)$ & $(0,092)$ & $(0,071)$ & $(0,513)$ & $(0,537)$ & $(0,315)$ & $(0,276)$ \\
\hline Desempleo (\%) & $-0,138$ & $-0,111$ & 0,139 & 0,113 & 0,311 & 0,378 & $-0,461^{* *}$ & $-0,453^{* *}$ \\
\hline PIB per cápita & $(0,128)$ & $(0,115)$ & $(0,068)$ & $(0,074)$ & $(0,162)$ & $(0,193)$ & $(0,171)$ & $(0,152)$ \\
\hline Intercepto en Y & $-0,002^{*}$ & $-0,002^{*}$ & $-0,0004^{*}$ & $-0,001^{*}$ & $-0,0002$ & $-0,0004$ & $-0,001^{*}$ & $-0,001^{* *}$ \\
\hline & $(0,001)$ & $(0,001)$ & $(0,0002)$ & $(0,0002)$ & $(0,0003)$ & $(0,0005)$ & $(0,0002)$ & $(0,0003)$ \\
\hline R & $74,724^{*}$ & $76,191^{*}$ & $25,869^{*}$ & $25,187^{*}$ & $34,600^{*}$ & $34,346^{*}$ & $40,917^{*}$ & $41,467^{*}$ \\
\hline R2 & $(2,826)$ & $(3,752)$ & $(0,661)$ & $(1,064)$ & $(1,848)$ & $(2,445)$ & $(3,275)$ & $(3,081)$ \\
\hline R2 Ajustado & 0,897 & 0,902 & 0,524 & 0,593 & 0,697 & 0,706 & 0,783 & 0,786 \\
\hline Prueba F & 0,805 & 0,813 & 0,275 & 0,351 & 0,486 & 0,498 & 0,613 & 0,618 \\
\hline N x T & 0,793 & 0,79 & 0,232 & 0,27 & 0,465 & 0,455 & 0,597 & 0,585 \\
\hline & $69,080^{*}$ & $34,340^{*}$ & $6,432^{*}$ & $4,329^{*}$ & $23,160^{*}$ & $11,660^{*}$ & $38,810^{*}$ & $18,980^{*}$ \\
\hline 72 & 72 & 73 & 73 & 103 & 103 & 103 & 103 \\
\hline
\end{tabular}

Notas:

La diferencia entre el modelo 1 y 2 es que en el segundo los años (tiempo) fue una variable ficticia ("dummy variable")

La pobreza monetaria (PM1 y PM2) de Argentina hace referencia a la zona urbana, el resto de los casos hace referencia a la pobreza nacional. Errores estándares corregidos (PCSE) en paréntesis.

Datos no disponibles para PM1, PM2, PC1 ni PC2: Bolivia 1990, Honduras 2000. Dato no disponible para PM1 ni PM2: Cuba 1990-2010, El Salvador 1990-1995, Jamaica 1990-2010, Panamá 1990-1995, Paraguay 1990-1995, Perú 1990, Republica Dominicana 1990-1995, Trinidad y Tobago 1990-2010, Uruguay 1990-2000. Dato no disponible para PM1: Ecuador 1990-1995. Dato no disponible para PM2: Nicaragua 1990. * Significación estadística en 0,01

** Significación estadística en 0,05

Fuente: Elaboración propia; FAO (2013); CEPAL (s/f); Heston et al. (2012); World Health Organization and United Nations Children's Fund (s/f); Banco Interamericano de Desarrollo (2014) y cálculos propios. 
Los resultados del coeficiente de correlación (R) entre gasto social per cápita y las medidas de pobreza fueron superiores a 0,69 con la excepción de los modelos con variable dependiente PM2. Los resultados del coeficiente de determinación $\left(\mathrm{R}^{2}\right)$ para las ocho regresiones realizadas en la serie temporal 1990-2010 fueron más variadas que con la anterior técnica. Ambos modelos de regresión con la variable dependiente PM1 presentaron un $\mathrm{R}^{2}$ superior a 0,89 ; con la variable $\mathrm{PM} 2$ valores superiores a 0,52 ; con la variable $\mathrm{PC} 1$ valores superiores a 0,69 ; y con la variable $\mathrm{PC} 2$ valores superiores a 0,78 . Nuevamente los modelos que consideraron la PM2 como variable dependiente fueron los que presentaron un coeficiente de determinación inferior, aunque la regresión con la otra variable monetaria de pobreza (PM1) fue la que presentó el mayor porcentaje de varianza explicada por el modelo. Los resultados denotan que sobre un $89 \%$ de la varianza de la PM1, 52\% de la varianza de la PM2 ${ }^{22}, 69 \%$ de la varianza de la PC1 y $78 \%$ de la varianza de la PC2, puede ser explicada por los respectivos modelos con gasto social per cápita como variable explicativa y controlando para factores demográficos y cíclicos. Los resultados del $\mathrm{R}^{2}$ ajustado fueron superiores a 0,45 en la totalidad de los modelos, nuevamente con la excepción de los modelos con variable dependiente PM2.

Utilizando el análisis de contraste de regresión se confirmó que el $p$-value fue menor de 0,01 en la totalidad de las regresiones con las cuatro variables dependientes de pobreza (PM1, PM2, PC1 y PC2). Por lo tanto se concluye que es muy poco probable que estos datos presenten un valor de $b=0$ y a su vez se confirman la alta significación de los modelos de regresión.

El gasto social per cápita aparenta ser importante para explicar diferencias en los niveles de pobreza entre los países de la muestra con el modelo 1 y 2 en la totalidad de las regresiones excepto en las que la PM2 fue la variable dependiente. El modelo con la variable PM1 fue altamente significativo ( $p$-value menor a 0,01$)$ mientras que los modelos con las variables de pobreza desde el enfoque de capacidades fueron significativos ( $p$-value menor a 0,05 ). La variable control población en edad avanzada aumentó drásticamente su grado de significación en comparación con la técnica 2, al presentar una relación altamente significativa $(0,01)$ con la variable dependiente PC2 en ambos modelos. Además la población en edad avanzada presentó una relación significativa $(0,05)$ con la variable dependiente PM1 y PC1 en ambos modelos, y con la PM2 en el modelo 2. Sin embargo la variable población desempleada solo fue significativa $(0,05)$ en ambos modelos de regresión con la variable dependiente PC2. Mientras que la variable control PIB per cápita presentó una relación altamente significativa $(0,01)$ con las variables dependientes PM1 y PM2 en ambos modelos, y con la variable PC2

${ }^{22}$ En los modelos del año 1990 y 1995 de la técnica 2, sobre el 70\% de la varianza de la PM2 era explicada por el modelo. Por lo tanto era de esperarse que al evaluar todos los datos de la serie temporal combinada — en vez de por quinquenios - la varianza explicada por el modelo de la PM2 en la técnica 3 fuera mayor que la varianza máxima explicada en la técnica 2. 
en el modelo 1 . Además de presentar una relación significativa $(0,05)$ con la variable dependiente PC2 el modelo 2.

Los resultados de la técnica 3 denotan que al incorporar controles al modelo de regresión el gasto social per cápita presenta facultades explicativas sobre la pobreza desde el enfoque monetario (PM1) y desde el enfoque de capacidades (PC1 y PC2). La relación entre el gasto social per cápita y la pobreza en la técnica 3 presentó una mayor significación que en la técnica 2, en donde esta relación fue solo significativa en tres momentos. También los modelos 1 y 2 de regresiones entre gasto social per cápita y las variables PM1 y PC2 presentaron valores del coeficiente de correlación y determinación elevados, por lo que se puede considerar que la relación entre estas variables dependientes y la explicativa además de significativa es elevada.

\section{Conclusión}

Continuar reduciendo los niveles de pobreza es uno de los principales retos en la región de Latinoamérica y el Caribe. En la actualidad se otorga una mayor atención a la pobreza desde el enfoque monetarista dejando a un lado la pobreza desde el enfoque de capacidades. En el presente estudio se realizó un análisis relacional entre el gasto social per cápita como indicador de la variable esfuerzo de bienestar, y la pobreza desde el enfoque monetario y de capacidades. Además se introdujeron tres controles al análisis de regresión entre la pobreza y el gasto social per cápita, para corroborar si estos alteran las facultades explicativas del gasto social per cápita sobre los niveles de pobreza.

Tras evaluar el marco teórico de las variables analizadas, se realizaron tres técnicas de regresión. En la primera de las tres técnicas se utilizó una regresión lineal ajustada por mínimos cuadrados para medir la relación entre gasto social per cápita y pobreza (el dato utilizado fue el promedio para el periodo temporal 1990-2010). El grado de relación negativa presentó una considerable fortaleza entre la variable explicativa y la PM1, PC1 y PC2. Además la varianza explicada de la pobreza monetaria (PM1) y de capacidades (PC1 y PC2) por el modelo fue de entre $62 \%$ y $75 \%$.

En la segunda de las técnicas se incluyó al análisis tres variables para controlar por factores demográficos y cíclicos. Además se evaluó el grado de relación entre las variables en 5 periodos temporales. El grado de relación negativa entre el gasto social per cápita y la pobreza monetaria y de capacidades mantuvo una considerable fortaleza — solo con la excepción de la PM2 en los años 2000, 2005 y 2010 - Los resultados denotan que sobre un $85 \%$ de la varianza de la PM1, 25\% de la varianza de la PM223, $58 \%$ de la varianza de la PC1 y $60 \%$ de la varianza de la PC2, puede ser explicada por los respectivos modelos. Sin embargo, la variable explicativa solo fue significativa

${ }^{23}$ Para 1990 y 1995 sobre el 70\% de la varianza de la PM2 era explicado por el modelo. 
para explicar diferencias en los niveles de pobreza para el año 1995 con el modelo PM2, para el 2005 con el modelo PC1 y para el 2010 con el modelo PC1. Mientras que el PIB per cápita presentó una mayor significación que la propia variable explicativa.

En la tercera de las técnicas se realizó un análisis transnacional de una serie temporal combinada de hasta 21 países, en donde se corrigieron los errores estándares de los paneles tras una regresión lineal ajustada por mínimos cuadrados (modelo 1) y una regresión lineal ajustada por mínimos cuadrados con los años fijos como variable ficticia (modelo 2). El grado de relación negativa presentó una considerable fortaleza entre el gasto social per cápita y la variable dependiente PM1, PC1 y PC2. Los resultados denotan que sobre un $89 \%$ de la varianza de la PM1, 52\% de la varianza de la PM2, $69 \%$ de la varianza de la PC1 y $78 \%$ de la varianza de la PC2, puede ser explicada por los respectivos modelos. Las variables presentaron una relación significativa, así que el gasto social per cápita aparenta ser importante para explicar diferencias en los niveles de pobreza monetario (PM1) y de capacidades (PC1 y PC2).

Los resultados confirman que efectivamente el gasto social es útil para explicar las cambios en la pobreza, ya que existe una alta correlación negativa entre las variables antes y después de controlar para factores demográficos y cíclicos. Es decir, se confirma una tendencia de que a mayor gasto social menor nivel de pobreza. Ahora bien, a diferencia del estudio de Caminada et al. (2012) las variables utilizadas como controles también presentaron facultades explicativas. En el estudio Caminada et al. (2012) tras evaluar la correlación entre el gasto social y la pobreza, utilizando los mismos tres controles del presente análisis, en 22 países de la OCDE para los años 1985-2005 se concluyó que el gasto social es la principal fuerza explicativa en cuanto a diferencias en los niveles de pobreza se refiere. En el citado estudio utilizaron un indicador de pobreza desde el enfoque monetario, similar al PM2 del presente análisis. Sin embargo, tras realizar las tres técnicas de regresión en el presente estudio se encontró que en la muestra latinoamericana y caribeña, la población en edad avanzada pero sobre todo el PIB per cápita presentaron una relación significativa y facultades explicativas con la pobreza. A diferencia de los países de la OCDE en el estudio de Caminada et al. (2012), en la muestra latinoamericana de esta investigación el gasto social per cápita no presentó una relación negativa con la PM2 (población con ingresos inferiores al 50\% de la mediana de ingresos).

De los datos y resultados se pueden dar respuesta a otras preguntas que se mencionaron en el transcurso del artículo. En primer lugar, los países que presentan un mayor esfuerzo de bienestar para el periodo 1990-2010 no son necesariamente los que menor nivel de pobreza tienen. Por ejemplo, Brasil presenta el tercer gasto social más elevado en promedio para 1990-2010; sin embargo ocupa la novena posición de PM1, séptima de PM2, decimocuarta de PC1, y decimotercera de PC2. Así como Brasil hay otros países que presentan niveles de gasto social que no corresponden con sus niveles de pobreza. Sin embargo, si hay una relación negativa significativa entre las dos varia- 
bles. En segundo lugar, se puede concluir que el gasto social per cápita es más útil para explicar los cambios en la pobreza desde el enfoque de capacidades. Esto ya que en la técnica tres la relación entre el gasto social y los dos indicadores de pobreza desde el enfoque de capacidades fue significativa. Mientras que la relación entre el gasto social y la PM1 fue altamente significativa, la relación entre el gasto social y la PM2 no fue significativa.

El gasto social per cápita en la región latinoamericana presenta una relación negativa y significativa con la pobreza. Sin embargo no puede ser la única herramienta para reducir los altos niveles de pobreza presentes en la región. La pobreza es multidimensional y para confrontarla desde el Estado hay que utilizar herramientas multidimensionales, no basta con solo invertir en la dimensión del gasto social.

En futuros trabajos será necesario aumentar el número de casos y grados de libertad del modelo para poder generar conclusiones más substanciales sobre las regresiones. Así mismo será necesario incorporar determinantes de la pobreza como variables explicativas, si se pretende examinar las causas y explicaciones de los niveles de pobreza en la región. Para esto será necesario construir modelos lo más representativo a la realidad incorporando variables que representen los factores políticos, demográficos, sociales y económicos considerados como determinantes de la pobreza. Por último, será relevante utilizar indicadores de pobreza multidimensional para así examinar las facultades explicativas del esfuerzo de bienestar, al operacionalizar la pobreza ya no solo como la privación de capacidades unidimensionales sino como la existencia de pobreza multidimensional.

\section{Bibliografía}

AlkiRe, S. (2002): Valuing Freedoms: Sen's Capability Approach and Poverty Reduction, Oxford, Oxford University Press.

AlkiRe, S., y R. Black (1997): “A Practical Reasoning Theory of Development Ethics: Furthering the Capabilities Approach”, Journal of International Development, 9 (2), pp. 263-279.

Alkire, S. y J. Foster (2009): "Counting and Multidimensional Poverty Measurement", OPHI Working Paper 32, Oxford, University of Oxford .

Alkire, S. y M.E. Santos (2010): “Acute Multidimensional Poverty: A New Index for Developing Countries”, OPHI Working Paper 38, Oxford, University of Oxford .

AmentA, E. (1993): "The State of the Art in Welfare State Research on Social Spending Efforts in Capitalist Democracies since 1960", American Journal of Sociology, 99 (3), pp. 750-763. 
Ames, B. (1987): Political Survival; Politicians and Public Policy in Latin America, Berkeley, University of California Press.

Bailey, D. y J.N. Katz (2011): "Implementing Panel-Corrected Standard Errors in R: The Pcse Package", Journal of Statistical Software, 42 (1), pp.1-11.

Banco Mundial (1990): World Development Report 1990: Poverty, Washington DC, Banco Mundial.

Banco Interamericano de Desarrollo (2014): Latin Macro Watch (LMW), Disponible en: $<$ http://www.iadb.org/en/research-and-data/latin-american-and-caribbean-macrowatch,8633.html> (Consulta: 21 de septiembre de 2015).

Beck, N. y J.N. Katz (1995): "What to Do (and Not to Do) with Time-Series Cross-Section Data", The American Political Science Review, 89 (3), pp. 634-647.

Bérgolo, M., M. Leites y G. Salas (2010): "Pobreza y Justicia Social: Concepto e Interrelaciones", Revista Quantum, III (2), pp. 4-25.

Brooks, C. y J. Manza (2007): Why Welfare States Persist: The Importance of Public Opinion in Democracies, Chicago, The University of Chicago Press.

Cameron, D.R. (1978): "The Expansion of the Public Economy: A Comparative Analysis", American Political Science Review, 72, pp. 1243-1261.

Caminada, K., K. Goudswaard y F. Koster (2012): "Social Income Transfers and Poverty: A Cross-Country Analysis for OECD Countries", International Journal of Social Welfare, 21 (2), pp. 115-126.

Cantillon, B., I. Marx y K. Van den Bosch (2003): “The Puzzle of Egalitarianism: About the Relationships between Employment, Wage Inequality, Social Expenditures and Poverty", European Journal of Social Security, 5 (2), pp. 108-127.

CÁrdenas Rodríguez, O.J. (2009): "Poverty Reduction Approaches in Mexico since 1950: Public Spending for Social Programs and Economic Competitiveness Programs", Journal of Business Ethics, 88 (2), pp. 269-281.

CAstles, F. (1985): The Working Class and Welfare, Sydney, Allen and Unwin.

CEPAL (s/f): CEPALSTAT. Disponible en: www.cepal.org. (Consulta: 21 septiembre de 2105).

Clark, D.A. (2002): Visions of Development: A Study of Human Values, Cheltenham, Edward Elgar.

Clark, D.A. (2003): "Concepts and Perceptions of Human Well-Being: Some Evidence from South Africa", Oxford Development Studies, 31 (2), pp. 173-196.

Comisión Europea (2009): Social Protection and Social Inclusion 2008: EU Indicators, Bruselas, Office for Official Publications of the European Communities.

Crewson, P. (2006): Applied Statistics Handbook. Disponible en:

$<$ http://www.acastat.com> (consulta: 21 de septiembre de 2015). 
Cruz-Martínez, G. (2014): "Welfare State Development in Latin America and the Caribbean (1970s-2000s): Multidimensional Welfare Index, Its Methodology and Results”, Social Indicators Research, 119 (3), pp.1295-1317.

Cruz-Martínez, G. (2015): "Balance alternativo de indicadores de pobreza en los ODM para América Latina y el Caribe: ¿Medir el éxito como aceleración del progreso o consecución de las metas?", Relaciones Internacionales, 28, pp. 11-36.

Dafermos, Y. y C. Papatheodorou (2012): "What Drives Inequality and Poverty in the EU? Exploring the Impact of Macroeconomic and Institutional Factors", International Review of Applied Economics, 27 (1), pp.1-22.

Desai, M. (1995): Poverty, Famine and Economic Development, Aldershot, Edward Elgar.

Díez Medrano, J. (1992): Métodos de Análisis Causal, Madrid, Centro de Investigaciones Sociológicas.

Esping-Andersen, G. (1990): The Three Worlds of Welfare Capitalism, Princeton, NJ, Princeton University Press.

EtXeberria, J. (1999): Regresión Multiple, (Cuadernos de Estadística), Salamanca, Editorial La Muralla.

FAO (2013): Food Security Indicators. Disponible en: www.fao.org (consulta: 21 de septiembre de 2015)

FAO, IFAD, y WFP (2013): The State of Food Insecurity in the World. The Multiple Dimensions of Food Security, Roma, FAO.

Feres, J.C. y X. Mancero (2001): "Enfoques para la Medición de la Pobreza. Breve Revisión de la Literatura”, en Comisión Económica para América Latina y el Caribe (CEPAL) (ed.), Serie Estudios Estadísticos y Prospectivos (Vol. 4), Naciones Unidas.

Gottschalk, P. y T. Smeeding (2000): "Empirical Evidence on Income Inequality in Industrialized Countries", en A. Atkinson y F. Bourguignon (eds.), Handbook of Income Distribution, New York, Elsevier-North Holland Publishers. pp. 261-308.

Heclo, H. (1974): Modern Social Politics in Britain and Sweden: From Relief to Income Maintenance, New Haven, Yale University Press.

Heston, A., R. Summers y B. Aten (2012): Penn World Table Version 7.1, Center for International Comparisons of Production, Income and Prices at the University of Pennsylvania.

Hicks, A. (1999): Social Democracy and Welfare Capitalism: A Century of Income Security Politics, Ithaca, NY, Cornell University Press.

Huber, E., T. Mustillo y J. D. Stephens (2008): "Politics and Social Spending in Latin America", The Journal of Politics, 70 (02), pp. 420-436.

Huber, E. y J.D. Stephens (2012): Democracy and the Left. Social Policy and Inequality in Latin America, Chicago, The University of Chicago Press. 
Jensen, C. (2011): "Less Bad Than Its Reputation: Social Spending as a Proxy for Welfare Effort in Cross-National Studies", Journal of Comparative Policy Analysis, 13 (3), pp. 327-340.

Josifidis, K., N. Supic y E.B. Pucar (2010): "Social Spending (in)Efficiency of the European Welfare Regimes in Reducing Poverty", Transformations in business \& Economics, 9 (1), pp. 322-338.

Kenworthy, L. (1999): "Do Social Welfare Policies Reduce Poverty? A Cross-National Assessment", Social Forces, 77 (3), pp. 1119-1139.

KMENTA, J. (1986): Elements of Econometrics, New York, Macmillan.

Korpi, W. (1983): The Democratic Class Struggle, Londres, Routledge \& Kegan Paul.

Kuklys, W. e I. Robeyns (2004): Sen's Capability Approach to Welfare Economics. Disponible en:

$<$ http://www.econ.cam.ac.uk/dae/repec/cam/pdf/cwpe0415.pdf> (Consulta: 21 de septiembre de 2015).

Morales, J. (1994): “Sociedad y Bienestar. El Concepto de Bienestar”, Anuario Filosófico, 27 (2), pp. 603.

Nolan, B. e I. Marx (2009): "Economic Inequality, Poverty and Social Exclusion”, en Wiemer Salverda, Brian Nolan y Timothy M. Smeeding (eds.), The Oxford Handbook of Economic Inequality, New York, Oxford University Press, pp. 315-341.

Nussbaum, M. (1990): “Aristotelian Social Democracy”, en Bruce Douglas, Gerald Mara y Henry Richardson (eds.), Liberalism and the Good, New York, Routledge, pp. 203-252.

Nussbaum, M. (1995): "Human Capabilities, Female Human Beings", en Martha C. Nussbaum y Jonathan Glover (eds.), Women, Culture and Development, Oxford, Clarendon Press, pp. 61-104.

Nussbaum, M. (2000): Women and Human Development: The Capabilities Approach, Cambridge, Cambridge University Press.

Nussbaum, M. (2003): "Capabilities as Fundamental Entitlement: Sen and Social Justice", Feminist Economics, 9 (2-3), pp. 33-59.

OECD (2008): Growing Unequal? Income Distribution and Poverty in OECD Countries. Disponible en: www.oecd.org. (Consulta: 21 de septiembre de 2015).

Olaskoaga, J., R. Alaez-Aller y P. Díaz-De-Basurto-Uraga (2013): "Beyond Welfare Effort in the Measuring of Welfare States", Journal of Comparative Policy Analysis, 15 (3), pp. 274-287.

Orloff, A.S. (1993): "Gender and the Social Rights to Citizenship: The Comparative Analysis of Gender Relations and Welfare States", American Sociological Review, 58 (3), pp. 303-328. 
Pampel, F. y J. Williamson (1989): Age, Class, Politics and the Welfare State, New York, Cambridge University Press.

PARKs, R.W. (1967): "Efficient Estimation of a System of Regression Equations When Disturbances are Both Serially and Contemporaneously Correlated", Journal of the American Statistical Association, 62 (318), pp. 500-509.

Robeyns, I. (2003): “Sen's Capability Approach and Gender Inequality: Selecting Relevant Capabilities", Feminist Economics, 9 (2-3), pp. 61-92.

RodRIK, D. (1998): “Why Do More Open Economies Have Bigger Governments?”, Journal of Political Economy, 106 (5), pp. 997-1032.

Rojo Abuín, J.M. (2007): Regresión Lineal Simple. Instituto de Economía y Geografía. Laboratorio de Estadistica. Disponible en:

$<$ http://humanidades.cchs.csic.es/cchs/web_UAE/tutoriales/PDF/Regresion\%20lineal\%20 simple_3.pdf $>$ (Consulta: 25 de septiembre de 2015).

Samuelson, P.A. (1974): "Complementary -an Essay on the 40th Anniversary of Hicks Allen Revolution in Demand Theory", Journal of Economic Literature, XII (4).

Scruggs, L. y J.P. Allan (2006): "The Material Consequences of Welfare States: Benefit Generosity and Absolute Poverty in 16 OECD Countries", Comparative Political Studies, 39, pp. 880-904.

Segura-Ubiergo, A. (2007): The Political Economy of the Welfare State in Latin America: Globalization, Democracy and Development, New York, Cambridge University Press.

Sen, A. (1983): "Poor, Relatively Speaking", Oxford Economic Papers, 35 (2), pp.153-169.

Sen, A. (1992): Nuevo Examen de la Desigualdad, Madrid, Alianza Editorial.

Sen, A.(1999): Development as Freedom, Oxford, Oxford University Press.

SкостоL, T. (1988): "The Limits of the New Deal System and the Roots of Contemporary Welfare Dilemmas", en Margaret Weir, Ann S. Orloff y Theda Skocpol (eds.), The Politics of Social Policy in the United States, New Jersey, Princeton University Press, pp. 293-312.

Sloan, J. y K. Tedin (1987): "The Consequences of Regime Type for Public Policy Outcomes", Comparative Political Studies, 20, pp. 98-124.

SmeEding, T. (2005): "Public Policy, Economic Inequality, and Poverty: The United States in Comparative Perspective", Social Science Quarterly, 86, pp. 955-983.

SmeEding, T. (2006): "Poor People in Rich Nations: The United States in Comparative Perspective", The Journal of Economic Perspectives, 20 (1), pp. 69-90.

Spicker, P. (2009): "Definiciones de Pobreza: Doce Grupos de Significados", en Paul Spicker,

S. Alvarez Leguizamón y D. Gordon (eds.), Pobreza: Un Glosario Internacional, Buenos Aires, CLACSO-CROP.

Stephens, J.D. (1979): The Transition from Capitalism to Socialism, Urbana, University of Illinois Press. 
Weir, M., Ann S. y T. Skocpol (1988): The Politics of Social Policy in the United States, New Jersey, Princeton University Press.

Wilensky, H.L. (1975): The Welfare State and Equality: Structural and Ideological Roots of Public Expenditure, Berkeley, University of California Press.

World Health Organization (WhO)/ UNICEF (s/f): Joint Monitoring Programme for Water Supply and Sanitation. Disponible en:

$<$ http://www.wssinfo.org $>$ (Consulta: 21 de septiembre de 2015). 